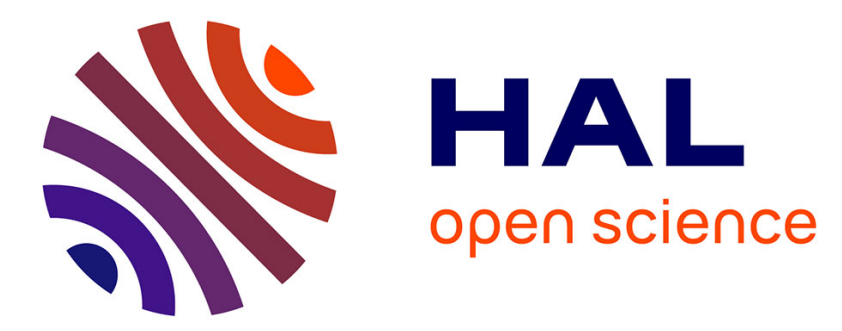

\title{
Redox properties of biscyclopentadienyl uranium(V) imido-halide complexes: a relativistic DFT study
}

Aziz Elkechai, Farida Kias, Fazia Talbi, Abdou Boucekkine

\section{To cite this version:}

Aziz Elkechai, Farida Kias, Fazia Talbi, Abdou Boucekkine. Redox properties of biscyclopentadienyl uranium(V) imido-halide complexes: a relativistic DFT study. Journal of Molecular Modeling, 2014, 20 (6), pp.2294. 10.1007/s00894-014-2294-5 . hal-01077363

HAL Id: hal-01077363

https://hal-univ-rennes1.archives-ouvertes.fr/hal-01077363

Submitted on 24 Oct 2014

HAL is a multi-disciplinary open access archive for the deposit and dissemination of scientific research documents, whether they are published or not. The documents may come from teaching and research institutions in France or abroad, or from public or private research centers.
L'archive ouverte pluridisciplinaire HAL, est destinée au dépôt et à la diffusion de documents scientifiques de niveau recherche, publiés ou non, émanant des établissements d'enseignement et de recherche français ou étrangers, des laboratoires publics ou privés. 


\title{
Redox Properties of Biscyclopentadienyl Uranium(V) Imido-Halide Complexes: A Relativistic DFT Study.
}

\author{
Aziz Elkechai ${ }^{\dagger}$, Farida Kias $^{\dagger}$, Fazia Talbi ${ }^{\dagger}$ and Abdou Boucekkine ${ }^{\ddagger *}$ \\ Laboratoire de Physique et Chimie Quantique, Faculté des Sciences, Université Mouloud \\ Mammeri, 15000 Tizi-Ouzou, Algeria. \\ Institut des Sciences Chimiques de Rennes, UMR 6226 CNRS-Université de Rennes 1, \\ Campus de Beaulieu, 35042 Rennes Cedex, France. \\ † Université Mouloud Mammeri \\ ¥ Université de Rennes 1
}

\section{Corresponding Author}

E-mail: abdou.boucekkine@univ-rennes1.fr 
Abstract: Calculations of ionization energies (IE) and electron affinities (EA) of a series of biscyclopentadienyl imido-halide uranium(V) complexes $C p{ }_{2}{ }_{2} U\left(=N-2,6-{ }^{i} \operatorname{Pr}_{2}-C_{6} H_{3}\right)(X)$ with $\mathrm{X}=\mathrm{F}, \mathrm{Cl}, \mathrm{Br}$ and $\mathrm{I}$, related to the $\mathrm{U}^{\mathrm{IV}} / \mathrm{U}^{\mathrm{V}}$ and $\mathrm{U}^{\mathrm{V}} / \mathrm{U}^{\mathrm{VI}}$ redox systems, were carried out, for the first time, using Density Functional Theory (DFT) in the framework of the relativistic Zeroth Order Regular Approximation (ZORA) coupled with the Conductor-like Screening Model (COSMO) solvation approach. A very good linear correlation $\left(R^{2}=0.993\right)$ was obtained, between calculated ionization energies at the ZORA/BP86/TZP level, and the experimental half-wave oxidation potentials $E_{1 / 2}$. A similar linear correlation between the computed electron affinities and the electrochemical reduction $\mathrm{U}^{\mathrm{IV}} / \mathrm{U}^{\mathrm{III}}$ potentials $\left(R^{2}=0.996\right)$ is obtained. The importance of solvent effects and of spin-orbit coupling is definitively confirmed. The molecular orbital analysis underlines the crucial role played by the $5 \mathrm{f}$ orbitals of the central metal whereas the Nalewajski-Mrozek $(\mathrm{N}-\mathrm{M})$ bond indices explain well the bond distances variations following the redox processes. The IE variation of the complexes, i.e. $\mathrm{IE}(\mathrm{F})<\mathrm{IE}(\mathrm{Cl})<\mathrm{IE}(\mathrm{Br})<\mathrm{IE}(\mathrm{I})$ is also well rationalized considering the frontier MO diagrams of these species. Finally, this work confirms the relevance of the Hirshfeld charges analysis which bring to light an excellent linear correlation $\left(R^{2}=0.999\right)$ between the variations of the uranium charges and $E_{1 / 2}$ in the reduction process of the $\mathrm{U}^{\mathrm{V}}$ species.

Keywords DFT; ZORA; uranium complexes; ionization energy; electron affinity; half-wave potentials; Hirshfeld analysis. 


\section{- INTRODUCTION}

Organoactinide complexes often present structural arrangements and a particular reactivity not noticed in coordination chemistry of transition metals [1-7]. The knowledge of the Electron Affinities (EA) and Ionization Energies (IE) of organoactinide complexes is essential for the understanding of the redox properties of these species, especially as actinides can exhibit various oxidation states. In particular, the study of the redox behaviour of uranium complexes, carrying the ubiquitous cyclopentadienyl ligand, is of great interest. Because redox experimental studies for actinide systems could be difficult to achieve, computational quantum chemistry provides useful tools to access to this important property. As pointed out in a rather exhaustive review devoted to EA by Rienstra-Kiracofe et al [8], electron affinities obtained with calibrated Density Functional Theory (DFT) methods are rather reliable and in good agreement with experiment.

The Kiplinger's group was pioneering in the theoretical determination of EA of fluoroketimide complexes [9]. The issues related to the scarcity, toxicity and handling of actinide complexes prevent experimental studies (to our knowledge, no direct experimental determination of EA of actinide complexes to date) which are limited to electrochemical measurements of the redox properties of uranium complexes [10-16]. Our previous studies of the redox behaviour of such species, concerning exclusively tetravalent organouranium complexes, namely the bis(cyclopentadienyl) series $\left[C{ }^{*}{ }_{2} U X_{2}\right]$ [17] and $\left[L_{2} U\left(B H_{4}\right)_{2}\right]$ [18], and tri(cyclopentadienyl) [CP $\left.{ }_{3} U X\right]$ [19], showed that DFT computed EAs correlate very well with the experimental half-wave reduction potentials $\left(R^{2} \geq\right.$ 0.99).

In 2008, the Los Alamos group provided a number of experimental data (structures, electrochemical measurements, IR spectra, NMR chemical shifts, magnetic susceptibility) for a series of unprecedented pentavalent uranium complexes [20]. This availability of experimental data on such rare compounds, expected to be unstable because their easy disproportionation into uranium(IV) and uranium(VI) species, gives us the opportunity to apply our methodology to the study of this new class of pentavalent complexes of uranium.

The purpose of the present work is to perform a detailed relativistic DFT study of the redox behavior of neutral imido halide uranium(V) complexes $\left[C{ }^{*}{ }_{2} U\left(=N-2,6{ }^{i}{ }^{P} r_{2}-C_{6} H_{3}\right)(X)\right](\mathrm{X}=\mathrm{F}, \mathrm{Cl}, \mathrm{Br}, \mathrm{I})$, through the determination of their electron affinities and ionization energies. In particular, we shall investigate what are the electronic factors which drive EAs and IPs of the $\mathrm{U}(\mathrm{V})$ complexes under consideration. Besides EAs and IEs, other molecular properties are discussed as molecular geometries, harmonic vibration frequencies and other electronic indices. In particular the Nalewajski-Mrozek [21] bond-multiplicity indices and the Hirshfeld electronic charge analysis [22] will be used to characterize the bonding and electronic structure of selected organouranium complexes. To our knowledge, it is the first time that a theoretical investigation of the oxidation of uranium complexes is done at the planned level of theory. 


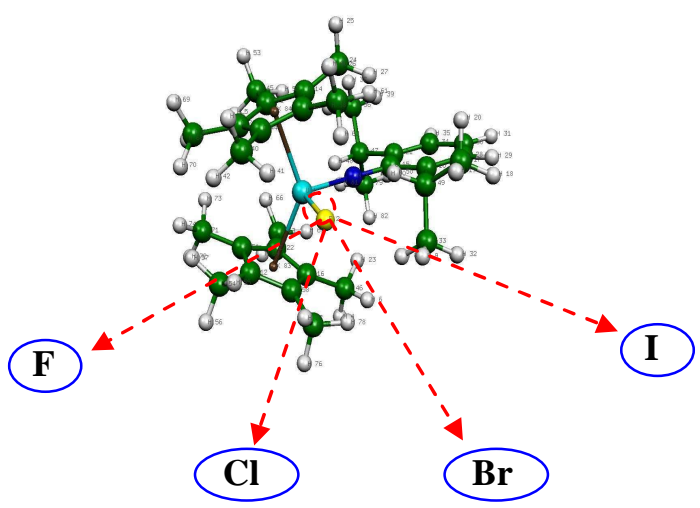

Fig. 1 The studied $C p^{*}{ }_{2} U\left(=N-2,6{ }^{i} \operatorname{Pr}_{2}--C_{6} H_{3}\right)(X)$ halide complexes

\section{- COMPUTATIONAL DETAILS}

In reference 8, it was shown, in the case of large polycyclic aromatic hydrocarbons, that standard DFT quantum chemical calculations with relatively small basis sets could reproduce experimental values of the electron affinities with average error of about $0.15 \mathrm{eV}$. Our previous studies, using Relativistic DFT [23] based on the Zeroth Order Regular Approximation (ZORA) [24] to the Dirac equation, showed that calculations carried out on bis (or tri)cyclopentadienyl uranium complexes lead to computed EAs in good agreement with experimental half-wave reduction potentials. So, in this work, we shall use the same methodology which is detailed below. The Vosko-Wilk-Nusair functional (WVN) [25] for the local density approximation (LDA) and the gradient corrections for exchange and correlation of Becke and Perdew [26] respectively, i.e. the BP86 functional have been used. Solvents effects have been taken into account using the Conductor-like Screening Model (COSMO) [27]. Geometry optimizations which have been carried out at the scalar relativistic level were followed by single point computations including spin orbit coupling. The calculations were performed using the Amsterdam Density Functional (ADF2010.02) program package [28c]. In this study, we used for all atoms a Triple- $\zeta$ Slater-type valence orbitals (STO) augmented by one set of polarization functions, i.e. the triple-zeta polarized (TZP) basis set, taken from the ADF/ZORA/TZP database. The spin unrestricted DFT scheme is used. The frozen-core approximation where the core density is obtained from four-component Dirac-Slater calculations has been applied for all atoms. For carbon C.1s, fluorine F.1s and nitrogen N.1s, the 1s core electrons were frozen. The $1 \mathrm{~s} / 2 \mathrm{~s} / 2 \mathrm{p}$ cores were frozen for the chlorine $\mathrm{Cl} .2 \mathrm{p}$, while the $1 \mathrm{~s} / 2 \mathrm{~s} / 2 \mathrm{p} / 3 \mathrm{~s} / 3 \mathrm{p} / 4 \mathrm{~s} / 3 \mathrm{~d}$ and $1 \mathrm{~s} / 2 \mathrm{~s} / 2 \mathrm{p} / 3 \mathrm{~s} / 3 \mathrm{p} / 4 \mathrm{~s} / 3 \mathrm{~d} / 4 \mathrm{p} / / 5 \mathrm{~s} / 4 \mathrm{~d}$ cores were frozen respectively for the bromine $\mathrm{Br} .3 \mathrm{~d}$ and iodine I.4d. The U.5d valence space of the heavy element includes the $5 \mathrm{f} / 6 \mathrm{~s} / 6 \mathrm{p} / 6 \mathrm{~d} / 7 \mathrm{~s} / 7 \mathrm{p}$ shells (14 valence electrons). Several studies have shown that the ZORA/BP86/TZP approach reproduces the experimental geometries and ground state properties of f-element compounds with a satisfying accuracy [29-31]. Molecular geometry and molecular orbital plots were generated, respectively, by using the MOLEKEL 4.3 [32] and the ADFVIEW [28c] programs.

Electron affinities (or ionization energies) are often not easily reachable experimentally; moreover, their computational evaluation is a difficult task owing to the fact that it implies odd-electron systems (spin contamination and SCF convergence problems). It should be noted that in our case, spin contamination was found negligible, owing to the fact that the computed values $\left\langle\mathrm{S}^{2}\right\rangle$ of the squared spin operator are very close to the exact values for all the studied species (deviation less than $3 \%$ ). 
In the present work, the electron affinities were calculated as the energy difference between the neutral and anionic (or cationic) forms of the complexes at their respective optimized geometries, i.e. the " $\Delta E$ method".

In terms of the energies $E$ at optimized geometries, EA and IE (Ionization Energy) are computed as follows:

$$
\begin{aligned}
& E A=E(\text { neutral })-E(\text { anion }) \text { for the reduction reaction, and } \\
& I E=E(\text { cation })-E(\text { neutral }) \text { for the oxidation reaction. }
\end{aligned}
$$

The ADF program that we use produces Total Bonding Energies (TBE) rather than total energies, so that EA is computed in our case as the $T B E$ (neutral) - TBE(anion) difference for the reduction process and IE as $T B E($ cation $)-T B E($ neutral).

\section{- RESULTS AND DISCUSSION}

Structural Properties. First, the full geometry optimizations of the neutral complexes $\left[C p^{*}{ }_{2} U\left(=N-2,6{ }^{i}{ }^{P} r_{2}-\right.\right.$ $\left.\left.\mathrm{C}_{6} \mathrm{H}_{3}\right)(\mathrm{F})\right](\mathbf{1}), \quad\left[\mathrm{Cp}{ }_{2}{ }_{2} U\left(=\mathrm{N}-2,6-{ }^{i} \mathrm{Pr}_{2}-\mathrm{C}_{6} \mathrm{H}_{3}\right)(\mathrm{Cl})\right](\mathbf{2}),\left[\mathrm{Cp}^{*}{ }_{2} U\left(=\mathrm{N}-2,6{ }^{i} \mathrm{Pr}_{2}-\mathrm{C}_{6} \mathrm{H}_{3}\right)(\mathrm{Br})\right]$ (3) and $\left[\mathrm{Cp}{ }_{2} \mathrm{U}(=\mathrm{N}-2,6-\right.$ $\left.\left.{ }^{i} \mathrm{Pr}_{2}-\mathrm{C}_{6} \mathrm{H}_{3}\right)(I)\right](4)$ and their anionic and cationic forms were carried out in the gas phase, at the spin unrestricted level of the theory. We considered the highest spin state for the anionic $\mathrm{U}^{\mathrm{IV}}\left(5 \mathrm{f}^{2}\right)$ complex, i.e. a triplet one, whereas the spin states are respectively a doublet state for the neutral $\mathrm{U}^{\mathrm{V}}\left(5 \mathrm{f}^{1}\right)$ species, and a singlet state for the cationic $\mathrm{U}^{\mathrm{VI}}\left(5 \mathrm{f}^{0}\right)$ one. All compounds have been taken in the $\mathrm{C}_{1}$ symmetry. Finally, in order to check that the optimized geometries are minima on the potential energy surfaces and to simulate IR spectra, we also performed the calculation of the vibration frequencies of the neutral $\mathrm{U}^{\mathrm{V}}$ species under consideration. Then, the geometries were further re-optimized in solution, using the COSMO approach, considering two different solvents (toluene which is the solvent used for the synthesis of the complexes, and tetrahydrofuran THF, used for the electrochemical measurements). The non-default Delley type of cavity was used, the solvents being considered with their dielectric constant respectively equal to of 2.38 and 7.58 for toluene and THF, whereas the cavity radius have been set equal to $3.48 \AA$ and $3.18 \AA$ for toluene and THF respectively. Finally, single-point variational spin-orbit ZORA calculations using the previously optimized geometries have been carried out, in both the gas phase and solution, in order to compute the spin-orbit coupling contributions to the energies [28b, 33]. In our case of open-shell systems, the non collinear approximation has been used [33b].

First of all, it is necessary to study the structures of the different species involved in the redox processes. In Table 1 are listed the most relevant computed geometrical parameters, i.e. metal-ligand distances and bond angles for the three $\mathrm{U}^{\mathrm{IV}}, \mathrm{U}^{\mathrm{V}}$ and $\mathrm{U}^{\mathrm{VI}}$ species in the gas phase as well as in solution at the ZORA/BP86/TZP level (the optimized structures and coordinates are given in Supporting Information (SI)). 
Table 1 Computed Distances ( $\AA$ ) and Angles (deg.) for the $\mathrm{U}^{\mathrm{IV}} / \mathrm{U}^{\mathrm{V}} / \mathrm{U}^{\mathrm{VI}} C_{p}{ }_{2}{ }_{2} \mathrm{U}\left(=\mathrm{N}-2,6-{ }^{i} \mathrm{Pr}_{2}-C_{6} H_{3}\right)(X)$ Complexes at the ZORA/BP86/TZP Level in the Gas Phase and in Solution (toluene), and the Available Experimental X-Ray Values for the Neutral $\mathbf{U}^{\mathrm{V}}$ Compounds (in Square Brackets) [20]

\begin{tabular}{|c|c|c|c|c|}
\hline Complex & $1(\mathrm{~F})$ & $2(\mathrm{Cl})$ & $3(\mathrm{Br})$ & $4(\mathrm{I})$ \\
\hline $\mathrm{U}-\mathrm{X}$ & $\begin{array}{c}2.147 / 2.110 / 2.084 \\
(2.157 / 2.115 / 2.086) \\
{[2.122(5)]}\end{array}$ & $\begin{array}{c}2.710 / 2.618 / 2.555 \\
(2.741 / 2.636 / 2.565) \\
{[2.6209(15)]}\end{array}$ & $\begin{array}{c}2.936 / 2.823 / 2.745 \\
(2.972 / 2.834 / 2.758) \\
{[2.789(3)]}\end{array}$ & $\begin{array}{c}3.254 / 3.100 / 3.001 \\
(3.302 / 3.137 / 3.016) \\
{[3.039(7)]}\end{array}$ \\
\hline $\begin{array}{c}\mathrm{U}-\mathrm{Cp}^{\mathrm{a}} \\
\text { (Centroid) }\end{array}$ & $\begin{array}{c}2.551 / 2.511 / 2.468 \\
(2.544 / 2.507 / 2.463)\end{array}$ & $\begin{array}{c}2.545 / 2.511 / 2.478 \\
(2.538 / 2.504 / 2.473)\end{array}$ & $\begin{array}{c}2.544 / 2.509 / 2.482 \\
(2.536 / 2.504 / 2.475)\end{array}$ & $\begin{array}{c}2.541 / 2.510 / 2.486 \\
(2.535 / 2.508 / 2.479) \\
{[2.457]}\end{array}$ \\
\hline $\mathrm{U}=\mathrm{N}$ & $\begin{array}{c}2.050 / 1.985 / 1.959 \\
(2.053 / 1.988 / 1.961) \\
{[1.965(8)]}\end{array}$ & $\begin{array}{c}2.038 / 1.978 / 1.952 \\
(2.038 / 1.980 / 1.954) \\
{[1.963(4)]}\end{array}$ & $\begin{array}{c}2.036 / 1.976 / 1.951 \\
(2.035 / 1.978 / 1.952) \\
{[1.969(7)]}\end{array}$ & $\begin{array}{c}2.031 / 1.974 / 1.949 \\
(2.028 / 1.975 / 1.951) \\
{[1.974(7)]}\end{array}$ \\
\hline $\mathrm{Cp}-\mathrm{U}-\mathrm{Cp}$ & $\begin{array}{c}134.6 / 136.4 / 148.9 \\
(133.9 / 137.3 / 148.1)\end{array}$ & $\begin{array}{c}134.2 / 139.1 / 144.7 \\
(134.4 / 135.7 / 144.2)\end{array}$ & $\begin{array}{c}133.6 / 135.9 / 141.4 \\
(133.4 / 135.2 / 144.2)\end{array}$ & $\begin{array}{c}134.4 / 135.5 / 140.8 \\
(130.0 / 131.6 / 142.2) \\
{[134.07]}\end{array}$ \\
\hline $\mathrm{N}=\mathrm{U}-\mathrm{X}$ & $\begin{array}{c}99.3 / 101.4 / 104.8 \\
(98.5 / 100.2 / 102.0)\end{array}$ & $\begin{array}{c}102.4 / 103.9 / 105.2 \\
(102.1 / 103.4 / 104.6) \\
{[105.8]}\end{array}$ & $\begin{array}{c}104.1 / 106.5 / 108.6 \\
(103.3 / 104.9 / 106.6) \\
{[105.3(2)]}\end{array}$ & $\begin{array}{c}106.1 / 107.7 / 110.1 \\
(105.1 / 107.1 / 108.4) \\
{[106.6(2)]}\end{array}$ \\
\hline $\mathrm{U}=\mathrm{N}-\mathrm{C}_{\mathrm{Ar}}$ & $\begin{array}{c}171.8 / 171.6 / 172.3 \\
(171.3 / 172.2 / 173.0)\end{array}$ & $\begin{array}{c}172.8 / 173.3 / 173.6 \\
(173.0 / 173.2 / 173.5) \\
{[169.6(4)]}\end{array}$ & $\begin{array}{c}172.8 / 173.0 / 171.9 \\
(173.1 / 173.4 / 173.3) \\
{[172.2(9)]}\end{array}$ & $\begin{array}{c}172.2 / 173.2 / 172.2 \\
(173.0 / 173.9 / 173.3) \\
{[170.7(6)]}\end{array}$ \\
\hline
\end{tabular}

a average values

As expected, all the mononuclear molecules $C p^{*}{ }_{2} U\left(=N-2,6-{ }^{i} \mathrm{Pr}_{2}-C_{6} H_{3}\right)(X)$ complexes are found in the familiar pseudo tetrahedral bent sandwich configuration with an usual geometry of the $U C p *_{2}$ fragment. The uranium coordination in these complexes features classic bent-metallocene geometry, with the imido-aryl and halide ligands contained within the metallocene wedge.

The computed geometrical parameters are globally found in good agreement with the available crystallographic data, namely those of $U^{\mathrm{V}}$ complexes $\mathbf{1}, \mathbf{2}, \mathbf{3}$ and 4 [20]. In particular, distances between central metal and the halide element U-X (2.110 $\AA$ for U-F, $2.618 \AA$ for U-Cl, $2.823 \AA$ for U-Br and $3.100 \AA$ for U-I) reproduce well the experimental data i.e. 2.122, 2.621, 2.789 and $3.039 \AA$, within the limit of the experimental error. Values of $\mathrm{U}-\mathrm{X}$ bonds which vary as follows $\mathrm{U}-\mathrm{F}<\mathrm{U}-\mathrm{Cl}<\mathrm{U}-\mathrm{Br}<\mathrm{U}-\mathrm{I}$ reflects well the ordering of the ionic radii of these elements. It is noticed that all halide $\mathrm{U}^{\mathrm{V}}$ complexes exhibit short $\mathrm{U}=\mathrm{N}_{\text {imido }}$ bond distances (1.974 to $1.985 \AA$ ) which correlate very well with the experimental values. One also finds the usual values of various angles like $135^{\circ}$ for $\mathrm{Cp} \mathrm{p}^{*}-\mathrm{U}-\mathrm{Cp}^{*}$ and 101 to $107^{\circ}$ for $\mathrm{N}=\mathrm{U}-\mathrm{X}$, with a better agreement for the $\mathrm{Cp} \mathrm{p}^{*} \mathrm{U}-\mathrm{X}$ angles (see Supporting Information). In addition, it is noted that the geometry of the $C p{ }_{2}^{*} U\left(=N-2,6-{ }^{i} \operatorname{Pr}_{2}-C_{6} H_{3}\right)$ moiety is not influenced by the nature of the $\mathrm{X}$ halide ligand; indeed, the $\mathrm{U}-\mathrm{C} \mathrm{p}_{\text {centroid }}(2.510 \AA), \mathrm{U}-\mathrm{C}$ and N-C $\mathrm{C}_{\mathrm{Ar}}$ distances are practically identical for the 4 studied compounds and are very close to the X-ray values; one notices also the almost linear arrangement of the atoms $\mathrm{U}=\mathrm{N}-\mathrm{C}_{\mathrm{Ar}}\left(\right.$ angles 171.6 to $\left.173.3^{\circ}\right)$. 
The electron capture by the neutral species leading to the U(IV) anionic complexes causes a lengthening of the distances between the central metal and its neighbors; this is mainly due to the increase of the ionic radius of uranium from $\mathrm{U}(\mathrm{V})$ to $\mathrm{U}(\mathrm{IV})$; on the contrary, the oxidation process induces a shortening of the metal-toligands bond lengths ( $c a .0 .3 \AA$ ). Moreover, it should be noted that oxidation affects rather clearly the angle between the $\mathrm{Cp}^{*}$ ring centroids and the central metal (it passes from $136^{\circ}$ in the neutral species to $149^{\circ}$ in the cationic species) whereas the $\mathrm{Cp}$ *centroid-U-X angles are not affected by the reduction or oxidation of the central metal ( $\mathrm{ca} .3^{\circ}$ for the angles). We also found that the optimized geometrical parameters in solution are close to the values obtained for the isolated molecules (values for the THF solvent in the SI).

The optimized molecular geometries of the anionic $\mathrm{U}^{\mathrm{IV}}$, neutral $\mathrm{U}^{\mathrm{V}}$, and cationic $\mathrm{U}^{\mathrm{VI}}$ complexes for $\mathrm{X}=\mathrm{Cl}$ (up) and $\mathrm{X}=\mathrm{F}$ (down), are depicted on Fig. 2.
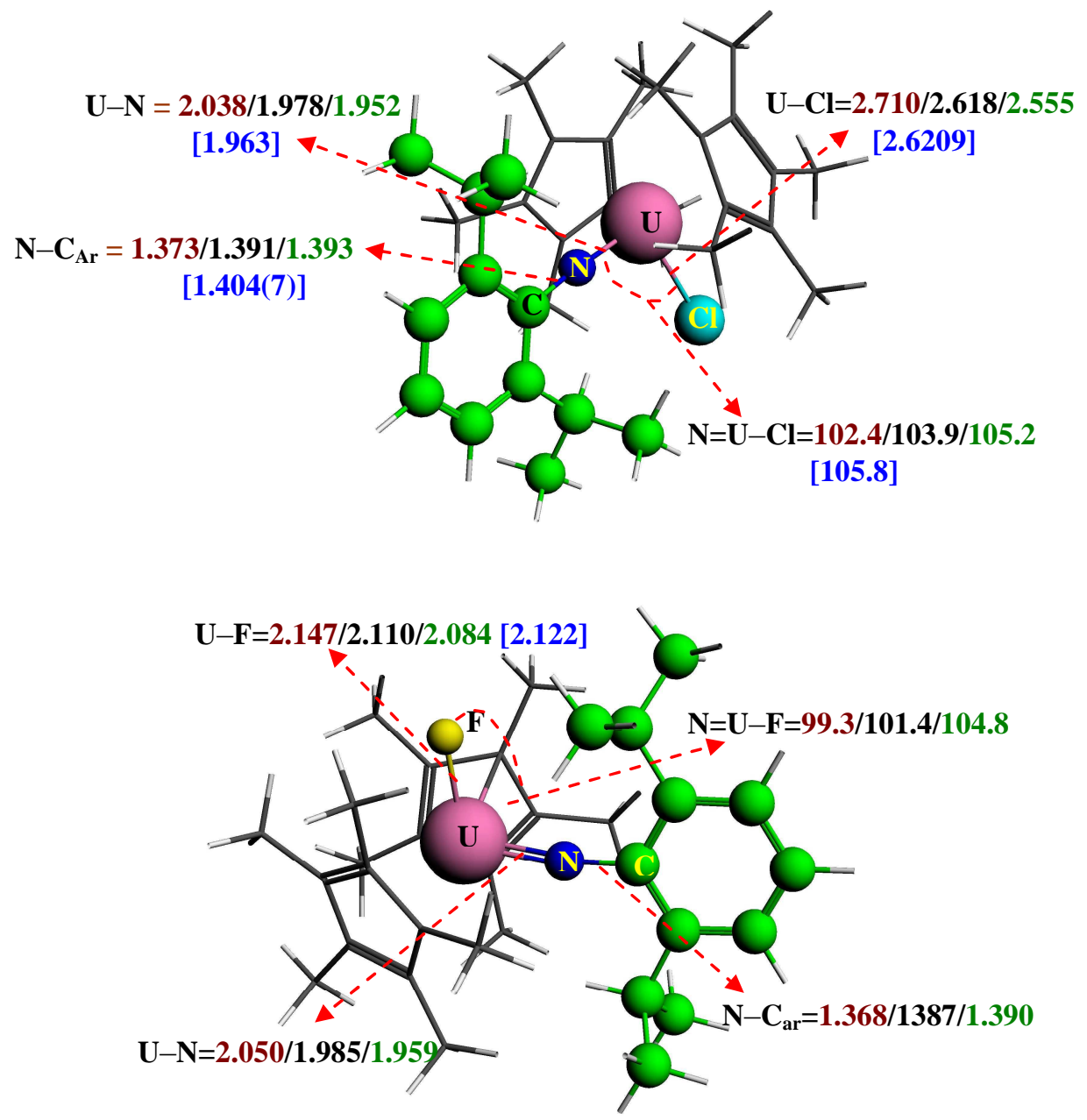

Fig. 2 Optimized geometries of the $\mathrm{U}^{\mathrm{IV}} / \mathrm{U}^{\mathrm{V}} / \mathrm{U}^{\mathrm{VI}} C \mathrm{Cp}_{2}{ }_{2} \mathrm{U}\left(=\mathrm{N}-2,6-{ }^{i} \mathrm{Pr}_{2}-C_{6} \mathrm{H}_{3}\right)(X)(\mathrm{X}=\mathrm{F}, \mathrm{Cl})$ complexes computed at the TZP level (isolated molecule). Hydrogen and carbon atoms of the $\mathrm{Cp}$ * rings are hidden for clarity (Geometries for $\mathrm{X}=\mathrm{Br}$, I are in SI) 
We consider now Nalewajski and Mrozek (NM) bond orders [21], which have been successfully used as a useful tool for the analysis of bonding and of the electronic structure of organometallic complexes [34]. Generally, the calculated NM bond orders correlate very well with experimental properties like bond lengths and vibrational frequencies. The imido-halide complexes present a single U-X bond (bond order equal to 0.999 for $\mathrm{F}, 1.037$ for $\mathrm{Cl}, 0.995$ for $\mathrm{Br}$ and 0.97 for I) whereas the bond order between the central metal and the nitrogen of the imido group is double of character (values between 1.83 and 2.25). On the other hand, this method predicts an increase in the $\mathrm{U}-\mathrm{X}$ and $\mathrm{U}-\mathrm{N}$ bond multiplicity in the cationic species, and a decrease in the anionic ones. These variations of NM bond orders increase with the atomic number of the halogen element; thus, the variation of these indices between the $\mathrm{U}^{\mathrm{IV}}$ and $\mathrm{U}^{\mathrm{V}}$ species is 0.0938 for $\mathrm{F}$, of 0.1970 for $\mathrm{Cl}, 0.2236$ for $\mathrm{Br}$, whereas it reaches 0.2758 for I (see detailed NM bond orders in SI). As expected, the changes in bond multiplicity are reflecting the changes in the bond-length, a higher bond order corresponding to a shorter bond length. Thus, an almost perfect linear correlation is obtained between the NM bond orders of the $\mathrm{U}-\mathrm{N}$ bonds and the corresponding U-N bond lengths $\left(R^{2}=0.99\right)$. The $\mathrm{U}-\mathrm{X}$ bonds present also such correlation but with $R^{2}=0.97$ (in $\mathrm{SI})$.

Calculations of the analytical vibrational frequencies of the neutral species reveal practically similar spectra for all the complexes. The simulated DFT spectra show two distinct bands, the first going from 0 to 1500 $\mathrm{cm}^{-1}$ with rather low IR intensities, and the second ranging between 2500 and $3250 \mathrm{~cm}^{-1}$. The latter, containing in particular two localized transitions around $2900 \mathrm{~cm}^{-1}$, corresponds to vibrational modes within the $\left[\mathrm{Cp}_{2}{ }_{-}-\mathrm{U}=\mathrm{N}-(2,6)-{ }^{i} \mathrm{Pr}_{2}-\mathrm{C}_{6} \mathrm{H}_{3}\right]$ moiety, whereas the $\mathrm{U}-\mathrm{X}$ vibration is localized in the first band. The stretching frequencies of the U-X bonds are respectively equal to 512, 543, 581 and $592 \mathrm{~cm}^{-1}$ for $\mathbf{1}(\mathrm{F}), \mathbf{2}(\mathrm{Cl}), \mathbf{3}(\mathrm{Br})$ and 4 (I).

Redox Properties. We consider first the oxidation of the neutral $\mathrm{U}^{\mathrm{V}}$ imido-halide complexes, half-wave oxidation potentials from electrochemical measurements, relative to the $\mathrm{U}^{\mathrm{V}} / \mathrm{U}^{\mathrm{VI}}$ redox system being available. In all cases, the IEs were computed according to the " $\Delta \mathrm{E}$ method", that is the difference between the TBEs of the cationic $\mathrm{U}^{\mathrm{VI}}$ and neutral $\mathrm{U}^{\mathrm{V}}$ species at their optimized geometries. In Table 2, are given the computed IEs, in the gas phase as well as in solution (toluene and THF) for all complexes, at the ZORA/BP86/TZP level of theory; the row with the acronym SO corresponds to the values of the IE taking into account spin-orbit coupling. In the last row of this Table, are displayed the experimental half-wave oxidation potentials in volts $\left(E_{1 / 2} \mathrm{vs}\left[\mathrm{Cp}_{2} \mathrm{Fe}\right]^{+/ 0}\right)$ of the neutral uranium(V) complexes, in THF) [20]. The computed TBE values are given in SI.

Table 2 Ionization energies $(\mathrm{eV})$ of the $\mathrm{U}^{\mathrm{V}} \mathrm{Cp}_{2}{ }_{2} \mathrm{U}\left(=\mathrm{N}-2,6-{ }^{i} \mathrm{Pr}_{2}-\mathrm{C}_{6} \mathrm{H}_{3}\right)(\mathrm{X})$ Complexes at ZORA/BP86/TZP Level in the Gas Phase and in Solution, i.e. in toluene and in THF (in parentheses), and the Experimental Half-Wave Oxidation Potentials $E_{1 / 2}(V)$ 


\begin{tabular}{cccccc}
\hline \multirow{2}{*}{ Complex } & $\mathbf{1}$ & $\mathbf{2}$ & $\mathbf{3}$ & $\mathbf{4}$ \\
& & $(\mathrm{F})$ & $(\mathrm{Cl})$ & $(\mathrm{Br})$ & $(\mathrm{I})$ \\
\hline \multirow{2}{*}{$\mathrm{TZP}$} & Gas phase & 5.507 & 5.587 & 5.619 & 5.659 \\
& Toluene & 4.851 & 4.941 & 4.972 & 5.120 \\
& THF & $(4.531)$ & $(4.618)$ & $(4.653)$ & $(4.691)$ \\
TZP/SO & Gas phase & 5.568 & 5.657 & 5.690 & 5.728 \\
& Toluene & 4.907 & 5.009 & 5.046 & 5.076 \\
\multicolumn{2}{c}{ Exp. $\boldsymbol{E}_{\mathbf{1 / 2}}(\mathbf{V})$} & $\mathbf{( 4 . 5 8 6 )}$ & $\mathbf{( 4 . 6 8 7 )}$ & $\mathbf{( 4 . 7 2 3 )}$ & $\mathbf{( 4 . 7 5 3 )}$ \\
& & $-\mathbf{0 . 1 4}$ & $\mathbf{0 . 0 3}$ & $\mathbf{0 . 0 7}$ & $\mathbf{0 . 1 1}$ \\
& & & & & \\
\hline
\end{tabular}

Considering the complexes in the gas phase, it can be noted in Table 2 that all the computed IEs are positive, their values being between 5.507-5.659 eV and between 5.568-5.728 eV when including spin-orbit coupling. The iodide compound, which has the highest half-wave oxidation potential $(+0.11 \mathrm{~V})$ exhibits the highest IE $(5.728 \mathrm{eV})$ and is therefore the most difficult to oxidize. On the contrary, the fluoride congener exhibits the lowest IE $(5.568 \mathrm{eV})$ and probes to be the easiest to oxidize. In addition, it can be seen that spinorbit coupling affects similarly the TBE of the neutral and cationic species, in their doublet and singlet state respectively, leading to an energy lowering of 2.17 to $2.35 \mathrm{eV}$ and a smaller increase of IE ( $0.07 \mathrm{eV}$ on average). The effect of a solvent leads to an important variation of IEs, even if their ordering is maintained, i.e. $\mathrm{IE}(\mathrm{F})<$ $\mathrm{IE}(\mathrm{Cl})<\mathrm{IE}(\mathrm{Br})<\mathrm{IE}(\mathrm{I})$.

Moreover, it can be seen that the IEs decrease with the solvent polarity; in our case, THF leads to the lowest IEs. A very nice linear correlation is obtained between the computed IEs (in THF at the TZP level including the spinorbit correction) and the experimental half-wave oxidation potentials $E_{1 / 2}$, the $R^{2}$ correlation coefficient of the linear regression being equal to 0.99 (Fig. 3). We note that neglecting solvation worsens slightly the IE- $E_{1 / 2}$ correlation $\left(R^{2}=0.98\right)$.

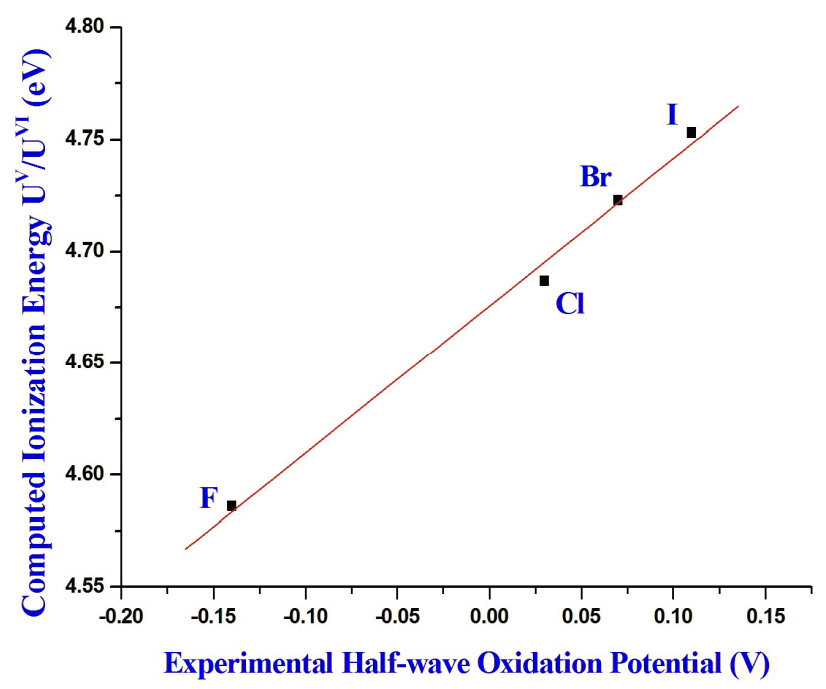

Fig. 3 Correlation between the computed ionization energies at the ZORA/BP86/TZP level in THF and the experimental half-wave oxidation potentials $E_{1 / 2}$. 
In Table 3, are reported the calculated energies of frontier orbitals, the SOMOs (Singly Occupied Molecular Orbital) of the $\mathrm{U}^{\mathrm{V}}$ complexes and the LUMOs (Lowest Unoccupied Molecular Orbital) of $\mathrm{U}^{\mathrm{VI}}$ ones, in the gas phase and in THF, as obtained in the scalar relativistic case, as well as spinors energies when taking into account the spin-orbit coupling.

Table 3 Computed SOMO and LUMO Energies (in eV) of the $U^{\mathrm{V}}$ and $\mathrm{U}^{\mathrm{VI}}$ Complexes, and Highest Occupied Spinors of $U^{V}$ and Lowest Unoccupied Spinors of $U^{V I}$ Energies (eV) at the ZORA/BP86/TZP level (Computed Values in THF Solution in Parentheses)

\begin{tabular}{ccccc}
\hline & \multicolumn{2}{c}{ Scalar ZORA Calculations } & \multicolumn{2}{c}{ Spin-Orbit ZORA Calculations } \\
\hline Complexes & $\mathrm{U}^{\mathrm{V}}$ SOMO & $\mathrm{U}^{\mathrm{VI}}$ LUMO & $\mathrm{U}^{\mathrm{V}}$ HOS & $\mathrm{U}^{\mathrm{VI}}$ LUS \\
\hline 1. fluoride & -3.413 & -6.549 & -3.676 & -7.080 \\
& $(-3.555)$ & $(-4.466)$ & $(-3.816)$ & $(-4.970)$ \\
\hline 2. chloride & -3.523 & -6.614 & -3.783 & -7.166 \\
& $(-3.676)$ & $(-4.523)$ & $(-3.920)$ & $(-5.073)$ \\
\hline 3. bromide & -3.565 & -6.679 & -3.824 & -7.205 \\
& $(-3.725)$ & $(-4.543)$ & $(-3.972)$ & $(-5.093)$ \\
\hline 4. iodide & -3.651 & -6.703 & -3.897 & -7.222 \\
& $(-3.804)$ & $(-4.598)$ & $(-4.041)$ & $(-5.130)$ \\
\hline
\end{tabular}

In the gas phase, the SOMO energies of the neutral $\mathrm{U}^{\mathrm{V}}$ complexes are negative, from -3.413 to -3.651 , and these energies undergo roughly the same slight reduction $(-0.15 \mathrm{eV})$ in THF. The iodide complex exhibits the lowest SOMO energy $(-3.651 \mathrm{eV})$ corresponding to the largest IE whereas its fluoride homolog exhibits the highest SOMO $(-3.413 \mathrm{eV})$ and the weakest IE of the considered series. On the other hand, the LUMO energies values of the cationic compounds are definitely negative (below $-6.5 \mathrm{eV}$ ), making these $\mathrm{U}^{\mathrm{VI}}$ species able to undergo a reduction process. Nevertheless, the MO energies of the cations are strongly destabilized by the presence of the THF solvent, their energies undergoing a significant increase (2.1 eV approximately). As expected, we observe a rather good linear correlation $\left(R^{2}=0.97\right.$, see SI) appears between the $\mathrm{U}^{\mathrm{V}}-\mathrm{SOMO}$ energies in solution and the experimental oxidation potentials $E_{1 / 2}$.

The effect of spin-orbit coupling is more pronounced for the SOMO energies of the neutral $\mathrm{U}^{\mathrm{V}}$ species (an average reduction of $0.25 \mathrm{eV}$ ) than for the LUMO energies of $\mathrm{U}^{\mathrm{VI}}$ complexes $(0.6 \mathrm{eV})$. Moreover, the spinor energies vary in the same way as the frontier orbitals energies and a good linear correlation is found between the $\mathrm{U}^{\mathrm{V}}$ HOS energies and the experimental oxidation potentials $E_{1 / 2}(\mathrm{SI})$.

The frontier molecular orbital (FMO) diagrams of both the neutral $\mathrm{Cp}^{*}{ }_{2} U\left(=\mathrm{N}-2,6-{ }^{i} \mathrm{Pr}_{2}-\mathrm{C}_{6} \mathrm{H}_{3}\right)(\mathrm{X})$ complexes and the corresponding cations are now considered in order to study the changes undergone by the electronic structures upon oxidation.

One will be particularly interested by the orbitals involved in this electronic loss, namely the SOMO of the neutral complex. Fig. 4 shows the FMO diagram of the neutral $\mathrm{U}^{\mathrm{V}}$ imido-halide complexes composed of two highest singly occupied orbitals, namely the SOMO and SOMO-1, and the empty LUMO, as computed at the 
scalar-relativistic level. These FMO are plotted with the percentages $(6 \mathrm{~d} / 5 \mathrm{f} / \mathrm{U} / \mathrm{N})$ indicating the weight of the $6 \mathrm{~d}$ and $5 \mathrm{f}$ metal orbitals as well as those of uranium and nitrogen atoms in the MOs (more detailed frontier MO correlation diagrams are given in the SI).
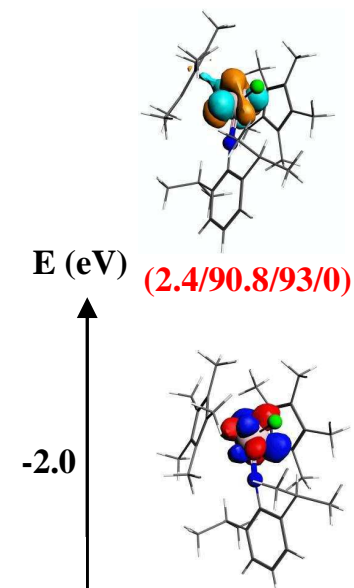

$(2.3 / 90.7 / 93 / 0)$

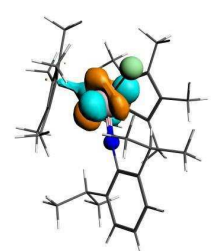

$(1.6 / 91.3 / 92.9 / 0)$

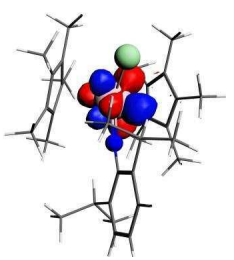

$(2.2 / 90.9 / 93.1 / 0)$

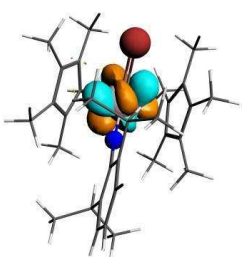

$(1.6 / 91.4 / 93 / 0)$

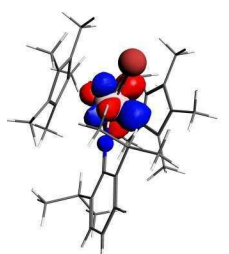

$(2.2 / 89.7 / 91.9 / 0)$

$\%(6 d / 5 f / U / N)$
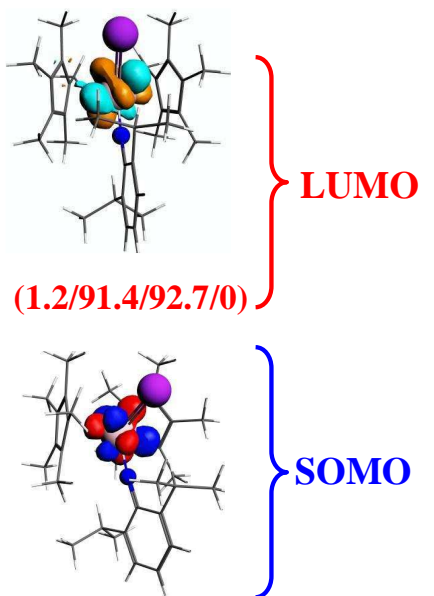

$(2.3 / 91.6 / 93.8 / 0)$

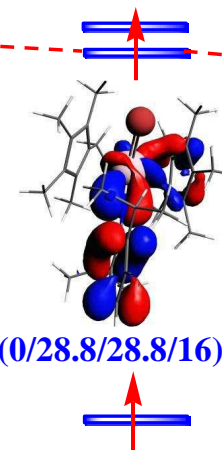

[3] Bromide

[4] Iodide

[1] Fluoride

[2] Chloride $\mathrm{X}=\mathrm{F}, \mathrm{Cl}, \mathrm{Br}, \mathrm{I}$
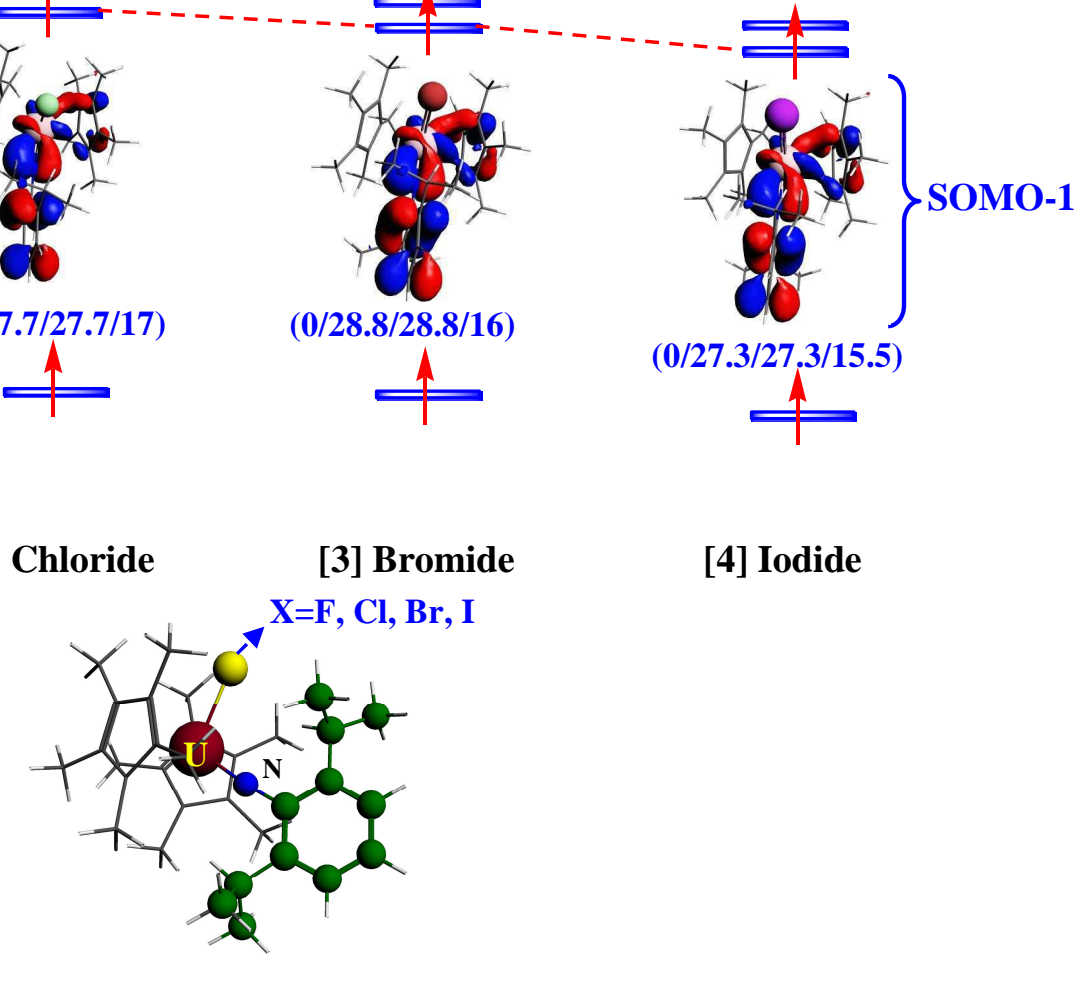

(0/27.3/27.3/15.5)

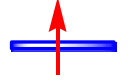

$-5.0$

$(0 / 25.1 / 25.1 / 16)$

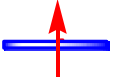

Fig. 4 Frontier $\alpha$-MO diagram of the imido-halide $U^{\mathrm{V}}$ complexes (scalar ZORA/BP86/TZP computations in THF). The dots connect the SOMO energy levels. 
All halide complexes present the same FMO diagram; the LUMO and SOMO exhibit mainly a uranium 5f character with a small contribution of the $\mathrm{Cp}^{*}$ rings; if the weight of nitrogen is zero in these orbitals, SOMO1 exhibits a very strong $\mathrm{U}=\mathrm{N} \pi$ bonding character (17\% of nitrogen contribution), while the $\mathrm{X}$ ligand contribution appears only starting from the SOMO-2 (3\% on average). Finally, in our case, oxidation can be considered as the loss of an electron by the metal ion which changes consequently its oxidation state (from $\mathrm{U}^{\mathrm{V}}$ to $\mathrm{U}^{\mathrm{VI}}$ ), as expected.

In Figure 5, is displayed the frontier MO diagram of the cationic U(VI) species, which are a closed-shell complexes.

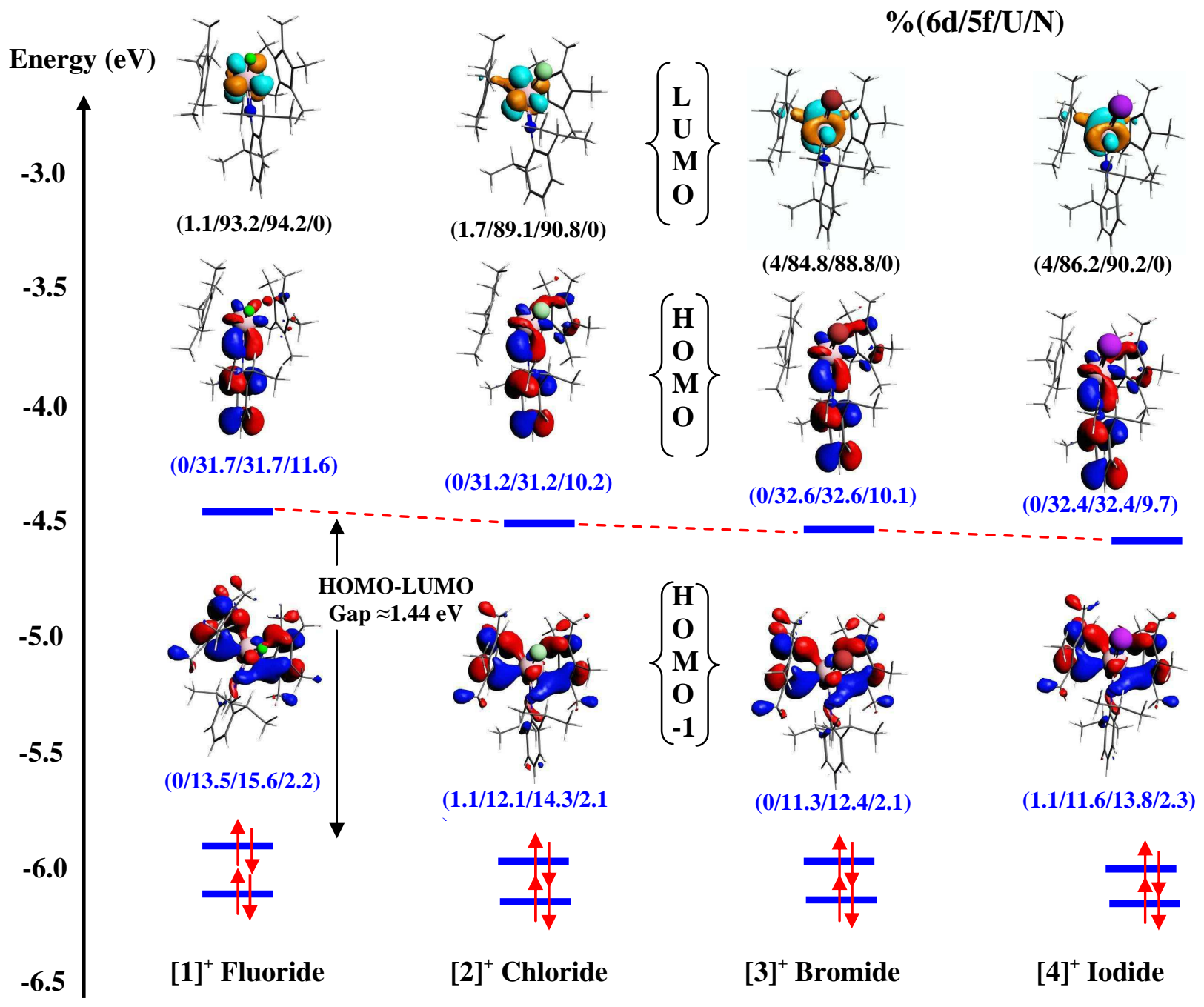

Fig. 5 Frontier MO diagram of the cationic $U^{\mathrm{VI}}$ complexes (scalar ZORA/BP86/TZP computations in solution). The dots connect the LUMO energy levels.

Fig. 5 shows a LUMO which is mainly a $5 \mathrm{f}$ metal orbital for all complexes, while the contribution of the uranium decreases reaching $32 \%$ in the HOMO which exhibits a significant U-N bonding character (10\% on average); the contribution of the X ligand is zero in all frontier MOs except in the bromide compound (1.7\% in 
HOMO). It is also interesting to note the large value of the HOMO-LUMO gap (1.44 eV on average) thus conferring to these species a relative thermodynamic stability.

Now, we examine the reduction of the neutral $\mathrm{U}^{\mathrm{V}}$ complexes. The EAs are computed as the difference between the TBEs of the neutral $\mathrm{U}^{\mathrm{V}}$ and anionic $\mathrm{U}^{\mathrm{IV}}$ species at their optimized geometries. The computed TBEs and EAs, in the gas phase as well as in solution (THF), for all complexes at the ZORA/BP86/TZP level of theory, are given in Table 4; the rows with SO correspond to the values of the TBE and EA taking account of spin-orbit coupling. In the last row, are displayed the experimental half-wave reduction potentials in volts $\left(E_{1 / 2}\right.$ vs. $\left[\mathrm{Cp}_{2} \mathrm{Fe}\right]^{+/ 0}$ ) of the neutral uranium(V) complexes, measured in THF) [20].

Table 4 Computed TBEs (eV) and EAs of the $\mathrm{U}^{\mathrm{IV}} / \mathrm{U}^{\mathrm{V}}$ redox couple of $C p^{*}{ }_{2} U\left(=N-2,6-{ }^{i} \operatorname{Pr}_{2}-C_{6} H_{3}\right)(X)$ Complexes at the TZP Level in the Gas Phase and in THF (in parentheses).

\begin{tabular}{|c|c|c|c|c|c|}
\hline Species & Complex & $\begin{array}{c}1 \\
(\mathrm{~F})\end{array}$ & $\begin{array}{c}2 \\
(\mathrm{Cl})\end{array}$ & $\begin{array}{c}\mathbf{3} \\
(\mathrm{Br})\end{array}$ & $\begin{array}{c}4 \\
\text { (I) }\end{array}$ \\
\hline $\mathrm{U}(\mathrm{IV})$ & $\begin{array}{l}\text { TZP } \\
\text { SO }\end{array}$ & $\begin{array}{c}-480.701 \\
(-482.319) \\
-483.007 \\
(-484.559)\end{array}$ & $\begin{array}{c}-478.769 \\
(-480.379) \\
-481.047 \\
(-482.665)\end{array}$ & $\begin{array}{c}-478.176 \\
(-479.781) \\
-480.398 \\
(-482.098)\end{array}$ & $\begin{array}{c}-477.480 \\
(-478.948) \\
-479.749 \\
(-481.428)\end{array}$ \\
\hline & TZP & $\begin{array}{c}1.594 \\
(2.864)\end{array}$ & $\begin{array}{c}1.819 \\
(3.083)\end{array}$ & $\begin{array}{c}1.890 \\
(3.151)\end{array}$ & $\begin{array}{c}2.006 \\
(3.137)\end{array}$ \\
\hline EA & SO & $\begin{array}{c}1.665 \\
(2.870)\end{array}$ & $\begin{array}{c}1.855 \\
(3.121)\end{array}$ & $\begin{array}{c}1.832 \\
(\mathbf{3 . 1 8 6})\end{array}$ & $\begin{array}{c}1.921 \\
(3.265)\end{array}$ \\
\hline$E_{1 / 2}$ & & -1.81 & -1.52 & -1.44 & -1.37 \\
\hline
\end{tabular}

As expected, the computed electron affinities calculated in gas phase are all positive since the TBEs of the anionic species in their triplet state are lower than those of their neutral parents in their doublet state. The fluoride complex, which has the lowest half-wave reduction potential $(-1.81 \mathrm{~V})$ exhibits the lowest EA (1.665 $\mathrm{eV}$ ) and is therefore the most difficult to reduce. On the contrary, its iodide congener exhibits the highest EA $(1.921 \mathrm{eV})$ and should be the easiest to reduce.

While the effects of the spin-orbit coupling affect similarly the TBEs of $\mathrm{U}^{\mathrm{V}}$ and $\mathrm{U}^{\mathrm{VI}}$ complexes, the corrections brought by the solvent are relatively significant and affect differently the TBE of the $\mathrm{U}^{\mathrm{V}}$ and $\mathrm{U}^{\mathrm{IV}}$ species inducing a substantial energy lowering of the order of $1.6 \mathrm{eV}$ for the anionic compounds and $0.35 \mathrm{eV}$ in average for the neutral precursors; this causes an important variation of the EAs. In the same way as for oxidation, we found an excellent linear correlation $\left(R^{2}=0.998\right)$ between the computed EAs (calculated in THF at the TZP level including the spin-orbit correction) and the experimental half-wave reduction potentials $E_{1 / 2}$ (Fig. $6)$. If the solvent effects are not taken into account the above correlation worsens significantly $\left(R^{2}=0.940\right)$. 


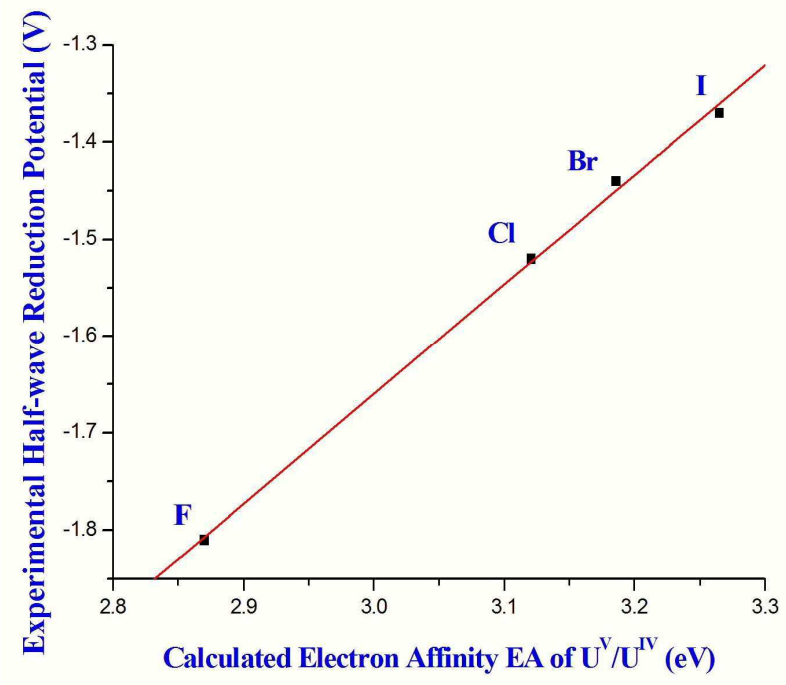

Fig. 6 Correlation between the computed electron affinities at the ZORA/BP86/TZP level in THF and the experimental half-wave potentials $E_{1 / 2}$ for the Halide complexes

The SOMO energies of the anionic species are positive in the gas phase, but become negative in THF, due to the stabilizing effect of the solvent. All the frontier MOs (Figure 7) i.e. the empty LUMO and the singly occupied SOMO and SOMO-1 exhibit a major $5 \mathrm{f}$ metallic character with a minor contribution of the $\mathrm{Cp}$ * rings, while the contribution of the $\mathrm{X}$ and $\mathrm{N}$ atoms are zero. In addition, the variation of the SOMO energies of the $\mathrm{U}^{\mathrm{IV}}$ species as well as the LUMO ones of the $\mathrm{U}^{\mathrm{V}}$ compounds, follows that of the EAs or of the reduction potentials, the lowest SOMO corresponding to the highest EA. Energies of the $\mathrm{U}^{\mathrm{IV}}-\mathrm{SOMO}$ and $\mathrm{U}^{\mathrm{V}}-\mathrm{LUMO}$ decrease according to the order: $\mathrm{I}>\mathrm{Br}>\mathrm{Cl}>\mathrm{F}$ and a good linear correlation is found between the $\mathrm{U}^{\mathrm{V}}$ LUMO energies and the experimental reduction potentials $E_{1 / 2}$ of the $\mathrm{U}^{\mathrm{V}} / \mathrm{U}^{\mathrm{IV}}$ pair $\left(R^{2}=0.98\right.$, see $\left.\mathrm{SI}\right)$. 


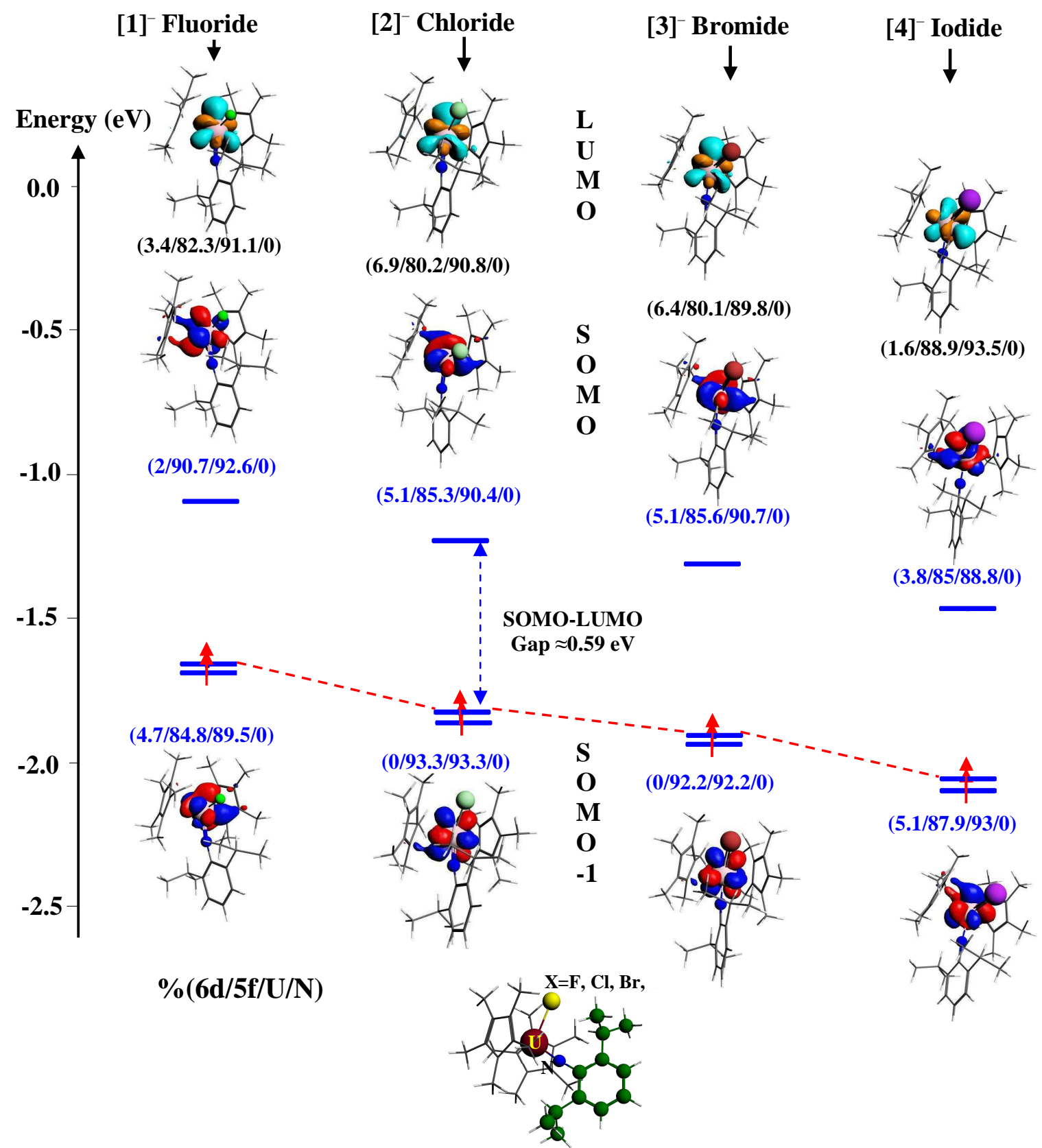

Fig. 7 Frontier $\alpha$-MO Diagram of the anionic U(IV) species computed at the ZORA/BP86/TZP level in solution. The dots connect the SOMO energy levels.

A final observation on the redox properties of these imido-halide $U(V)$ uranium complexes is that the energy range between the metal-based oxidation $(\mathrm{U}(\mathrm{V}) / \mathrm{U}(\mathrm{VI}))$ and reduction $(\mathrm{U}(\mathrm{V}) / \mathrm{U}(\mathrm{IV}))$ is found almost the same for all the studied complexes : $\Delta\left(\mathrm{TBE}_{\text {redox }}\right)=\mathrm{IE}+\mathrm{EA} \approx 7.8 \mathrm{eV}$. This trend was first observed experimentally by Kiplinger's group [20] who noted that the difference of the half-wave potentials of the $\mathrm{U}(\mathrm{VI}) / \mathrm{U}(\mathrm{V})$ and $\mathrm{U}(\mathrm{V}) / \mathrm{U}(\mathrm{IV})$ redox processes of eight imido-halide uranium complexes was practically constant: $\Delta E_{1 / 2}=E_{1 / 2}\left(\mathrm{U}^{\mathrm{VI}} / \mathrm{U}^{\mathrm{V}}\right)-E_{1 / 2}\left(\mathrm{U}^{\mathrm{V}} / \mathrm{U}^{\mathrm{IV}}\right)=1.51 \mathrm{~V}$. 
Mulliken Population Analysis (MPA) and Hirshfeld Charge Analysis of the $\mathrm{Cp}^{*}{ }_{2} U\left(=\mathrm{N}-2,6{ }^{i} \mathrm{Pr}_{2}-\mathrm{C}_{6} \mathrm{H}_{3}\right)(\mathrm{X})$ series bring light on some other aspects of the metal-ligands interaction. Despite its well know limitations, MPA permits to describe qualitatively the evolution of charge transfers and bonding interactions occurring in a series of homologous molecular systems. In Table 5, are collected the computed Mulliken metal spin populations and Hirshfeld charges of $\mathrm{U}, \mathrm{X}$ atoms and $\mathrm{Cp}^{*}{ }_{2}+\mathrm{N}$-Aryl ligands of the anionic, neutral and cationic $C p{ }_{2} U(=N-2,6$ $\left.{ }^{i} \mathrm{Pr}_{2}-\mathrm{C}_{6} \mathrm{H}_{3}\right)(\mathrm{X})$ species. The numbers $-1,0$ and +1 indicate respectively the anionic U(IV), the neutral U(V) and the cationic $\mathrm{U}(\mathrm{VI})$ species. Metal spin population is calculated as the difference between the total $\alpha$ and $\beta$ electronic populations of the metal. By net charges of $\mathrm{Cp}^{*}{ }_{2}$ and $\mathrm{N}$-Aryl, one understands the global charge of the two $\mathrm{Cp}^{*}$ rings and the imido-aryl moiety respectively and not only that of the atom connected to uranium.

Table 5 Mulliken metal spin density and Hirshfeld Charges of $C p^{*}{ }_{2} U\left(=N-2,6-{ }^{i} r_{2}-C_{6} H_{3}\right)(X)$ Complexes (scalar ZORA/BP86/TZP computations in THF).

\begin{tabular}{|c|c|c|c|c|c|}
\hline \multirow{2}{*}{ Complex } & \multirow{2}{*}{$\begin{array}{c}\text { Complex } \\
\text { charge }\end{array}$} & MPA & \multicolumn{3}{|c|}{ Hirshfeld Charges } \\
\hline & & $\begin{array}{l}\text { Metal spin } \\
\text { density }\end{array}$ & $\mathrm{U}$ & $\mathrm{X}$ & {$\left[\mathrm{Cp}^{*}{ }_{2}+\mathrm{N}-\mathrm{Aryl}\right]$} \\
\hline \multirow{3}{*}{$\begin{array}{c}1 \\
\text { Fluoride }\end{array}$} & -1 & 2.22 & +0.5672 & -0.2828 & -1.2843 \\
\hline & 0 & 1.28 & +0.6694 & -0.2421 & -0.4273 \\
\hline & +1 & 0.00 & +0.7391 & -0.1977 & +0.4585 \\
\hline \multirow{3}{*}{$\stackrel{2}{\text { Chloride }}$} & -1 & 2.25 & +0.5349 & -0.2856 & -1.2490 \\
\hline & 0 & 1.30 & +0.6185 & -0.1962 & -0.4221 \\
\hline & +1 & 0.00 & +0.6791 & -0.1022 & +0.4232 \\
\hline \multirow{3}{*}{$\stackrel{3}{\text { Bromide }}$} & -1 & 2.26 & +0.5363 & -0.3014 & -1.2347 \\
\hline & 0 & 1.31 & +0.6141 & -0.1952 & -0.4188 \\
\hline & +1 & 0.00 & +0.6702 & -0.0790 & +0.4083 \\
\hline \multirow{3}{*}{$\begin{array}{c}\mathbf{4} \\
\text { Iodide }\end{array}$} & -1 & 2.22 & +0.5288 & -0.3261 & -1.2029 \\
\hline & 0 & 1.33 & +0.6014 & -0.1902 & -0.4112 \\
\hline & +1 & 0.00 & +0.6455 & -0.0325 & +0.3872 \\
\hline
\end{tabular}

The Mulliken analysis (detailed in SI) indicates that the net charges of the metal are largely smaller than its oxidation state $(+6,+5$ and +4 for the cationic, neutral and anionic species respectively) due to the ligands to metal donation, the latter effect being highlighted by the weak negative charges carried by the $\mathrm{X}^{-}, \mathrm{Cp}^{*}{ }_{2}$ and $\mathrm{N}-$ aryl ligands. In particular, the $\mathrm{Cp}_{2}{ }_{2}$ net charge increases considerably with the oxidation state of the metal; the oxidation processes $\left(\mathrm{U}^{\mathrm{IV}} \rightarrow \mathrm{U}^{\mathrm{V}} \rightarrow \mathrm{U}^{\mathrm{VI}}\right.$ ) induce a significant transfer of electron density from the $\mathrm{Cp}^{*}$ ligands to the metal, the charge carried by these rings, being largely positive $($ of +1.1 to +1.3$)$ in the cationic species. In addition, for all neutral and anionic complexes, it is worth to note a weak delocalization of the unpaired electrons. The MPA metal spin population is indeed slightly larger than 1 for the neutral $5 f^{1} U(V)$ species, larger than 2 for the anionic $5 f^{2} \mathrm{U}(\mathrm{IV})$. Thus, the DFT computations indicate 2.22 unpaired electrons on central metal for the fluoride complex in solution with minor spin populations on the $\mathrm{Cp}^{*}{ }_{2}$ and $\mathrm{N}$-Aryl ligands while the spin 
density is 1.28 for the anionic species. The spin population data for the isolated molecules are practically similar to those computed in solution.

Another quantitative approach of the major electron transfers occurring in molecular systems is provided by Hirshfeld's analysis (HA) [22], which is supposed to give more realistic net charges than MPA, agreeing well with chemical intuition [35]. As already noticed with MPA, the ligand-to-metal donation increases with the uranium oxidation state; this is highlighted by the decrease of the net charges of the ligands. For example, in the fluoride complex, the sum of net charges carried by the three bulky ligands (i.e. the two $\mathrm{Cp}^{*}$ rings and the imidoaryl moiety), which is definitely negative $(-1.29)$ in the anionic species, passes to -0.43 in the neutral molecule, and become positive $(+0.46)$ in the cationic species. Thus, the HA reproduces the same tendency than MPA ($1.30,-0.34$ and +0.71 respectively with MPA, values in SI), but leads to a relatively lower net charge for the $\mathrm{U}^{\mathrm{VI}}$ species. On the other hand, HA is more realistic than MPA concerning the net charges carried by the uranium; logically, these uranium charges increase slightly with the oxidation state of the central metal.

Table 6 Hirshfeld charge variation of $U, X$ and $N$ atoms after the $U^{\mathrm{V}} \rightarrow U^{\mathrm{IV}}$ reduction process calculated for an isolated molecule and in THF (between parentheses)

\begin{tabular}{cccc}
\hline Ligand/Complex & $\delta q(X)$ & $\delta q(U)$ & $\delta q\left\{(C p)_{2}^{*}+N A r\right\}$ \\
\hline 1. Fluoride & $-0.0381(-0.0407)$ & $-0.1025(-0.1022)$ & $-0.8594(-0.8571)$ \\
\hline 2. Chloride & $-0.0785(-0.0894)$ & $-0.0842(-0.0836)$ & $-0.8373(-0.8270)$ \\
\hline 3. Bromide & $-0.0934(-0.1062)$ & $-0.0780(-0.0778)$ & $-0.8286(-0.8160)$ \\
\hline 4. Iodide & $-0.1251(-0.1359)$ & $-0.0680(-0.0726)$ & $-0.8069(-0.7915)$ \\
\hline
\end{tabular}

Finally, as showed by the values in Table 6, it is worth noting that the variations of the uranium Hirshfeld charges of the different complexes when passing from the U(V) to the U(IV) complexes correlates very well with the half-wave reduction potentials of these species, the $R^{2}$ correlation coefficient being equal to 0.999 (see Fig. 8). Indeed, the differences between the uranium Hirshfeld charges in the $\mathrm{U}^{\mathrm{V}}$ and $\mathrm{U}^{\mathrm{IV}}$ species (Table 6) are the following, 0.1022, 0.0836, 0.0778 and 0.0726 respectively for $\mathrm{X}=\mathrm{F}, \mathrm{Cl}, \mathrm{Br}$ and $\mathrm{I}$. A rather good correlation $\left(R^{2}=0.971\right)$ is also obtained between the halide Hirshfeld charge variation and the experimental reduction potential.

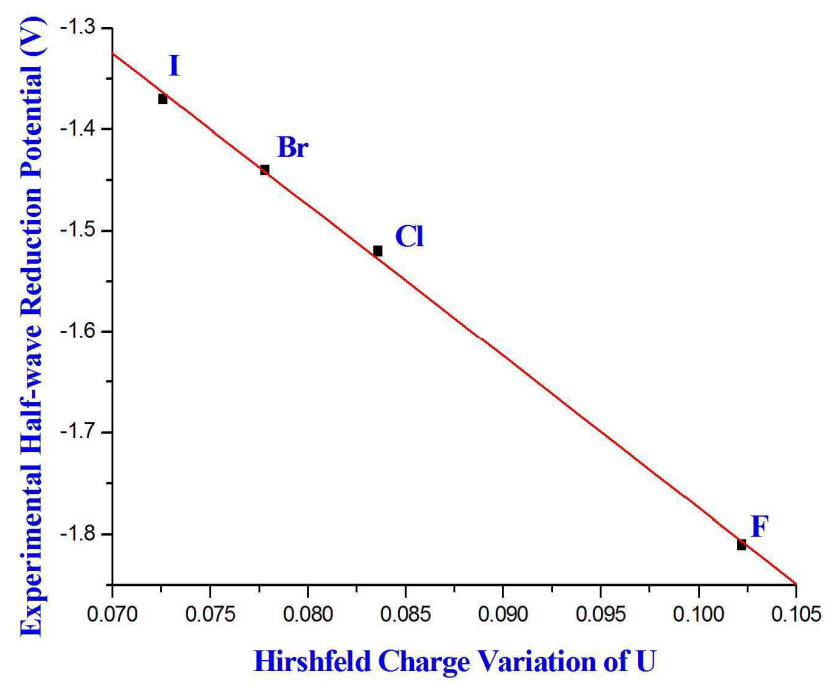


Fig. 8 Uranium Hirshfeld charge variation following the $\mathrm{U}^{\mathrm{V}} / \mathrm{U}^{\mathrm{IV}}$ reduction $v s$. experimental half-wave reduction potentials (scalar ZORA/BP86/TZP computations in THF)

A similar result was obtained in previous study of $\mathrm{L}_{3} \mathrm{UCl}$ complexes [36].

\section{- CONCLUSION}

The redox behavior of a series of biscyclopentadienyl imido-halide uranium(V) complexes $C p *{ }_{2} U(=N$ 2,6- $\left.{ }^{i} \mathrm{Pr}_{2}-\mathrm{C}_{6} \mathrm{H}_{3}\right)(\mathrm{X})(\mathrm{X}=\mathrm{F}, \mathrm{Cl}, \mathrm{Br}$ and $\mathrm{I})$ have been investigated for the first time, using relativistic ZORA/BP86 computations including spin-orbit coupling, solvent effects being taken into account using the COSMO solvation model. A very good linear correlation $\left(R^{2}=0.99\right)$ was found between the computed ionization energies (IE) and the experimental half-wave oxidation potentials $E_{1 / 2}$; in addition, as expected, a similar good correlation was found between the computed electron affinities (EA) and the measured electrochemical reduction potentials $\left(R^{2}=\right.$ 0.99). These main results confirm thus the reliability of the ZORA/DFT technique to study the redox processes of uranium complexes. Our study brings to light the importance of spin-orbit coupling and solvent effect which must be taken into account in order to achieve the best agreement between theory and experiment. Moreover, MO diagrams and population analyses permitted to understand the evolution of the computed IE and EA with the nature of the halide $\mathrm{X}^{-}$ligand. Indeed, considering the frontier MOs of the $\mathrm{U}^{\mathrm{V}}$ species, it can be seen that energetically the highest SOMO and LUMO are those of the fluoride complex, leading to the lowest IE and AE for this species. Finally, the Nalewajski-Mrozek bond order and the Hirshfeld charges analyses permit also to well rationalize the effect of the redox processes on structural properties. Indeed, on one hand, the NM methodology explains well the bond distances variations, while the HA approach leads, on the other hand, to an excellent correlation $\left(R^{2}=0.998\right)$ between the Hirshfeld charges variation of uranium atom following the $\mathrm{U}^{\mathrm{V}} / \mathrm{U}^{\mathrm{IV}}$ process and the half-wave reduction potentials $E_{1 / 2}$.

\section{SUPPORTING INFORMATION:}

SI.1: Optimized coordinates for isolated and solvated molecules

SI.2: Optimized structures of $\mathbf{3}$ and $\mathbf{4}$ complexes

SI.3: Nalewajski-Mrozek Bond Order Analysis

SI.4: Total Bonding Energies

SI.5: SOMO Energy vs. Oxidation Potential Correlation

SI.6: HOSpinor of $\mathrm{U}^{\mathrm{V}}$ vs. Oxidation Potential Correlation

SI.7: Frontier MO interaction diagram of the $U^{\mathrm{V}}$ complexes in THF; Correlation LumoUV-E1/2 red

SI.8: Mulliken Populations Analysis and Nalewajski-Mrozek Bond Orders 


\section{- ACKNOWLEDGMENTS}

The authors acknowledge the financial support from the Algerian Project CNEPRU ${ }^{\circ}$ D00520130051. Computing facilities were provided by GENCI-IDRIS and GENCI-CINES. The COST CM-1006 action is also acknowledged.

\section{- REFERENCES}

1. Boucekkine A, Belkhiri L (2013), f-element complexes, in: Jan Reedijk and Kenneth Poeppelmeier, Editors. Comprehensive Inorganic Chemistry II, Vol 9 (Editor S. Alvarez). Oxford: Elsevier, pp. 277-319

2. Ephritikhine M (2013), Recent Advances in Organoactinide Chemistry As Exemplified by Cyclopentadienyl Compounds Organometallics 32:2464-2488

3. Edelman F (1995). In: Abel EW, Stone FGA, Wilkinson G (ed) Comprehensive organometallic chemistry, vol. 4, Pergamon, Oxford, chapter 2, pp. 11

4. Burns CJ, Eisen MS (2006). In: Morss LR, Edelstein NM, Fuger F (ed), 3rd edn. The chemistry of the actinides and transactinides elements, vol. 5, Dordrecht, The Netherlands, , pp 2799

5. Evans WJ, Kozimor SA (2006). Coord Chem Rev 250:911

6. (a) Ephritikhine M (2006) Dalton Trans 2501. (b) Ephritikhine M (2008) Actual Chim 322, II

7. (a) Rogers RD, Rogers LM (1992) J Organomet Chem 442:225

(b) Rogers RD, Rogers LM (1993) J Organomet Chem 457:41

8. Rienstra-Kiracofe JC, Tschumper GS, Schaefer HF, Nandi S, Ellison GB (2002) Chem Rev 102:231

9. Schelter EJ, Yang P, Scott BL, Thompson JD, Martin RL, Hay PJ, Morris DE, Kiplinger JL (2007) Inorg Chem 46:7477

10. (a) Thomson RK, Scott BL, Morris DE, Kiplinger JL (2010) C R Chimie 13:790 (b) Graves CR, Vaughn AE, Schelter EJ, Scott BL, Thompson JD, Morris DE, Kiplinger JL (2008) Inorg Chem 47:11879 (c) Jantunen KC, Burns CJ, Castro-Rodriguez I, Da Re RE, Golden JT, Morris DE, Scott BL, Taw FL, Kiplinger JL (2004) Organometallics 23:4682 (d) Morris DE, Da Re RE, Jantunen KC, Castro-Rodriguez I, Kiplinger JL (2004) Organometallics 23:5142 (e) Kiplinger JL, Morris DE, Scott BL, Burns CJ (2002) Organometallics 21:3073

11. Finke RG, Gaughan G, Voegeli R (1982) J Organomet Chem 229:179

12. Mugnier Y, Dormond A, Laviron E (1982) J Chem Soc, Chem Commun 257

13. Sonnenberger DC, Gaudiello JG(1988) Inorg Chem 27:2747

14. Ossola F, Zanella $P$, Ugo $P$, Seeber R (1988) Inorg Chim Acta 147:123

15. (a) Hauchard D, Cassir M, Chivot J, Ephritikhine M (1991) J Electroanal Chem 313:227 (b) Hauchard D, Cassir M, Chivot J, Baudry D, Ephritikhine M (1993) J Electroanal Chem 347:399

16. Schnabel RC, Scott BL, Smith WH, Burns CJ (1999) J Organomet Chem 591:14

17. Elkechai A, Meskaldji S, Boucekkine A, Belkhiri L, Bouchet D, Amarouche M, Clappe C, Hauchard D, Ephritikhine M (2010) J Mol Struct (THEOCHEM) 954:115

18. Elkechai A, Boucekkine A, Belkhiri L, Hauchard D, Clappe C, Ephritikhine M (2010) C R Chimie 13:860

19. Elkechai A, Boucekkine A, Belkhiri L, Amarouche M, Clappe C, Hauchard D, Ephritikhine M (2009) Dalton Trans 2843 
20. Graves CR, Yang P, Kozimor SA, Vaughn AE, Clark DL, Conradson SD, Schelter EJ, Scott BL, Thompson JD, Hay PJ, Morris DE, Kiplinger JL (2008) J Am Chem Soc 130:5272

21. (a) Nalewajski RF, Mrozek J (1994) Int J Quantum Chem 51:187 (b) Michalak A, DeKock RL, Ziegler T (2008) J Phys Chem A $112: 7256$

22. Hirshfeld FL (1977) Theoret Chim Acta 44:129

23. (a) Hohenberg P, Kohn W (1964) Phys Rev 136 B864 (b) Kohn W, Sham LJ (1965) Phys Rev 140 A1133

(c) Parr RG, Yang W (1989) Density functional theory of atoms and molecules. Oxford University Press, UK

24. (a) van Lenthe E, Baerends EJ, Snijders JG (1993) J Chem Phys 99:4597 (b) van Lenthe E, Baerends EJ, Snijders JG (1994) J Chem Phys 101:9783 (c) van Lenthe E, Ehlers A, Baerends EJ (1999) J Chem Phys 110:8943

25. Vosko SD, Wilk L, Nusair M (1990) Can J Chem 58:1200

26. (a) Becke AD (1986) J Chem Phys 84:4524 (b) Becke AD (1988) Phys Rev A 38:3098 (c) Perdew JP (1986) Phys Rev B 33:8822 (d) Perdew JP (1986) Phys Rev B 34:7406 (e) Perdew JP, Wang Y (1992) Phys Rev B 45:13244

27. (a) Klamt A, Schürmann G (1993) J Chem Soc Perkin Trans 2:799 (b) Klamt A (1995) J Phys Chem 99:2224 (c) Klamt A, Jones V (1996) J Chem Phys 105:9972 (d) Klamt A, Jones V, Bürger T, Lohrenz JC (1998) J Phys Chem A 102:5074 (e) Delley B (2006) Mol Simul 32:117 (f) Klamt A (2005) COSMO-RS from quantum chemistry to fluid phase thermodynamics and drug design. Elsevier, Amsterdam, The Netherlands, ISBN 0-444-51994-7

28. (a) Fonseca GC, Snijders JG, te Velde G, Baerends EJ (1998) Theor Chem Acc 99:391 (b) te Velde G, Bickelhaupt FM, van Gisbergen SAJ, Fonseca GC, Baerends EJ, Snijders JG, Ziegler T (2001) J Comput Chem 931 (c) ADF2008.01, SCM, Theoretical Chemistry. Vrije University, Amsterdam, the Netherlands http://www.sm.com.

29. Ricciardi G, Rosa A, Baerends EJ, van Gisbergen SAJ (2002) J Am Chem Soc 124:1233

30. (a) Kaltsoyannis N (2003) Chem Soc Rev 32:9 (b) Shamov GA, Schreckenbach G (2005) J Phys Chem A 109:10961

31. (a) Roger M, Belkhiri L, Thuéry P, Arliguie T, Fourmigué M, Boucekkine A, Ephritikhine M (2005) Organometallics 24:4940 (b) Benyahia M, Belkhiri L, Boucekkine A (2006) J Mol Struct (Theochem) 777:61 (c) Meskaldji S, Belkhiri L, Arliguie T, Fourmigué M, Ephritikhine M, Boucekkine A (2010) Inor Chem 49:3192-3200 (d) Meskaldji S, Belkhiri A, Belkhiri L, Boucekkine A, Ephritikhine M (2012) C R Chimie 15:184-191

32. MOLEKEL4.3, Flükiger P, Lüthi HP, Portmann S, Weber J. Swiss Center for Scientific.

33. Shannon RD (1976) Acta Crystallogr Sect A 32:751

34. Michalak A, DeKook RL, Ziegler T (2008) J Phys Chem A 112:7256

35. Fonseca Guerra C, Handgraaf JW, Baerends EJ, Bickelhaupt FM (2004) J Comput Chem25 :189-210

36. Elkechai A, Mani Y, Boucekkine A, Ephritikhine M (2012) Inorg Chem 51 12:6943 